\title{
Surface Treatments for Improving Bond Strength to Prefabricated Fiber Posts: A Literature Review
}

\author{
F Monticelli $\bullet$ R Osorio $\bullet$ FT Sadek \\ I Radovic • M Toledano • M Ferrari
}

\begin{abstract}
Clinical Relevance
Several surface treatments have been proposed for improving the bonding of resin cements or core materials to FRC (fiber-reinforced composite) posts. The possibility of combining chemical and micromechanical retention on post surface provides the most promising adhesion mechanism.
\end{abstract}

Francesca Monticelli, DDS, MSc, PhD, vice dean and professor, Department of Surgery, Faculty of Health and Sport Sciences, University of Zaragoza, Huesca, Spain

Raquel Osorio, DDS, PhD, professor, Department of Dental Materials, Colegio Maxímo, University of Granada, Granada, Spain

Fernanda Tranchesi Sadek, DDS, MSc, PhD, post-doctoral researcher, Department of Dental Materials, Universidade de São Paulo (USP), SP, Brazil

Ivana Radovic, DDS, MSc, clinical assistant, Clinic of Pediatric and Preventive Dentistry, Faculty of Dentistry, University of Belgrade, Serbia and PhD student, Department of Restorative Dentistry and Dental Materials, Policlinico Le Scotte, University of Siena, Siena, Italy

Manuel Toledano, MD, DDS, PhD, professor, Department of Dental Materials, Colegio Maxímo, University of Granada, Granada, Spain

* Marco Ferrari, MD, DDS, PhD, dean and professor, Department of Restorative Dentistry and Dental Materials, Policlinico Le Scotte, University of Siena, Siena, Italy

*Reprint request: Policlinico Le Scotte, Viale Bracci, 53100, Siena, Italy; e-mail: md3972@mclink.it

DOI: $10.2341 / 07-86$

\section{SUMMARY}

This literature review summarizes the research on fiber post surface treatments and provides information related to their benefit in enhancing bond strength to composites, based on the results of original scientific full papers from peerreviewed journals listed in $\mathrm{Pub} \mathrm{Med}$. The search was conducted using the terms "fiber post," "surface treatment," "surface conditioning," "etching" and "sandblasting." A consistent number of in vitro studies that investigated the surface treatment of fiber posts in an attempt to improve bond strength have been published to date. Their results have been summarized in the following categories: chemical treatments and micromechanical treatments of fiber post surfaces (or a combination of both principles). The majority of available literature data is based on studies that investigated different "chairside" post superficial treatments. According to the in vitro results, surface conditioning improves fiber post bonding properties, and the bond strength of pre- 
treated fiber posts to restorative materials is satisfactory. Long-term clinical studies are needed prior to making a general recommendation for their use.

\section{INTRODUCTION}

Fiber posts are widely used to restore endodonticallytreated teeth that have insufficient coronal tooth structure to retain a core for the definitive restoration. ${ }^{1}$ Many in vitro studies have investigated factors that may affect the retention of a post. These factors may include design, length, diameter and surface treatments. ${ }^{2-5}$

The retention of fiber post and composite restorations depends on the quality of the bond established at different interfaces. Several investigations have been conducted to evaluate the interface with dentin, both at the coronal and radicular levels. ${ }^{6-8}$

Since the introduction of fiber posts, a continuous effort has been made to improve bonding inside the root canal: despite the development of novel adhesive systems, radicular dentin still offers less favorable conditions for bonding than coronal dentin. ${ }^{9-10}$

Chersoni and others ${ }^{11}$ recently reported that the bonding efficacy of simplified hydrophilic adhesives to autocured composites/cements is hampered by the intrinsic permeability of these adhesives to water still present in pulpless teeth.

The most frequent cause of adhesive failure is debonding of a post restoration at the resin cement/dentin interface. ${ }^{12-14}$

Although adhesion in the root canal represents the weakest point of the restoration, the post/composite adhesion needs to be considered. Immediately after fiber post cementation and core build-up, the restoration has to resist the stresses transmitted during core trimming to adapt the provisional crown..$^{15}$ At the coronal level, the amount of residual tooth structure still offers more favorable conditions for ensuring strong adhesion and retention. ${ }^{16-17}$

At the post-core interfacial level, only the chemical interaction between the fiber post surface and the composite may ensure the bond of the core material around the post.

In an attempt to maximize resin bonding to fiber posts, several surface treatments have been recently suggested. These procedures fall into three categories: 1) treatments that result in chemical bonding between a composite and post (coating with priming solutions); 2 ) treatments that intend to roughen the surface (sandblasting and etching) or 3) combine micromechanical and chemical components either by using the two above mentioned methods or a unique system (such as Co-Jet).
This literature review summarizes the results of the research conducted on fiber post surface treatments and provides information on their benefit for improving bonding to resin composites based on the results of original scientific full-papers from peer-reviewed journals listed in Pub Med. This search was conducted using the terms "fiber post," "surface treatment," "surface conditioning," "etching" and "sandblasting."

\section{LITERATURE DATA}

Silanization and/or adhesive application is undoubtedly the most thoroughly investigated fiber post-surface treatment in the current literature. The vast majority of articles published in Medline-cited journals investigated the effectiveness of these chairside procedures for improving bond strength. Limited information is available on chemo-mechanical surface treatments used in the attempt to enhance/modify the surface area available for bonding. All published articles are based on in vitro investigations. The selected investigations have been primarily performed using microtensile and pushout bond strength tests in combination with microscopic analysis. Few investigations include aging procedures in their experimental design, such as thermocycling and/or water storage (Table 1).

\section{Chemical Bonding to Fiber Posts}

Several studies suggest using silane coupling agents in coating applications to promote adhesion between inorganic surfaces and polymeric molecules. ${ }^{18-20}$

Organosilanes have the formula R'-Si- $(\mathrm{OR})_{3}$, with an organic functional group ( $\left.\mathrm{R}^{\prime}\right)$ and three alkoxy groups

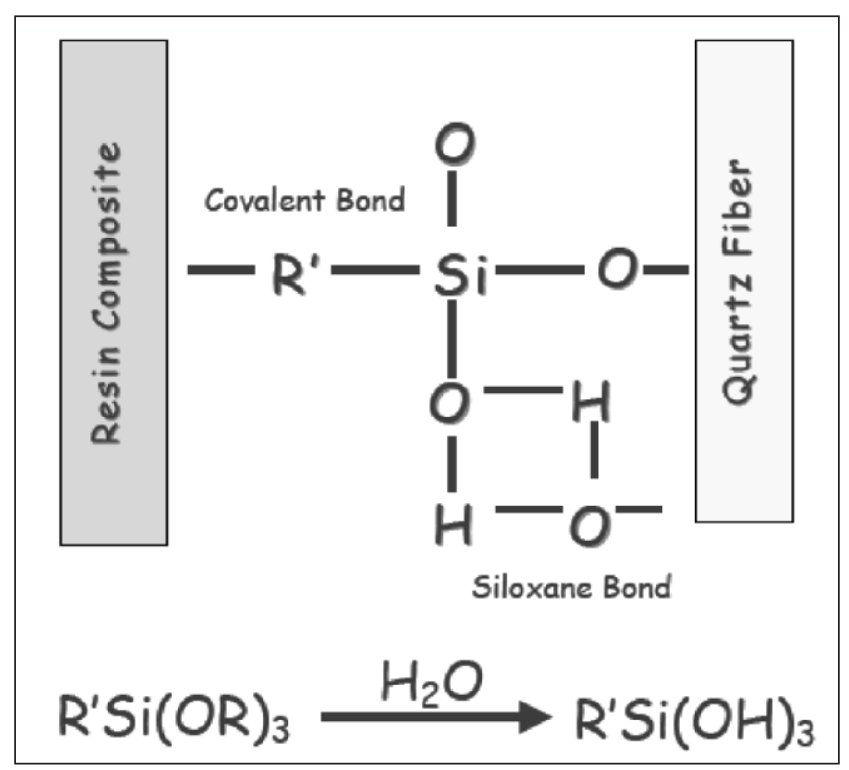

Figure 1. Representative drawing of the coupling reaction at the fiber post-composite interface. Organosilanes with chemical formula R'-Si$(O R)_{3}$ have an organic functional group ( $\left.R^{\prime}\right)$ and three alkoxy groups $(R)$ : the reaction begins with hydrolysis of the alkoxide groups $(R)$ into silanols ( $\mathrm{SiOH})$ that condense, forming siloxane bonds. 


\begin{tabular}{|c|c|c|c|}
\hline Selection Criteria & Authors & Superficial Treatment & Experimental Design \\
\hline \multirow[t]{7}{*}{ Chemical Bonding } & $\begin{array}{l}\text { Aksornmuang and } \\
\text { others, } 2004^{27}\end{array}$ & Adhesive application; silanization & $\begin{array}{l}\text { Microtensile bond strength test; } \\
\text { SEM analysis }\end{array}$ \\
\hline & $\begin{array}{l}\text { Aksornmuang and } \\
\text { others, } 2006^{28}\end{array}$ & Adhesive application; silanization & $\begin{array}{l}\text { Microtensile bond strength test; } \\
\text { SEM analysis }\end{array}$ \\
\hline & $\begin{array}{l}\text { Bitter and others, } \\
2007^{26}\end{array}$ & Silanization & Push-out bond strength test \\
\hline & $\begin{array}{l}\text { Ferrari and others, } \\
2006^{45}\end{array}$ & Adhesive application; silanization & $\begin{array}{l}\text { Microtensile bond strength test; } \\
\text { SEM analysis }\end{array}$ \\
\hline & $\begin{array}{l}\text { Goracci and others, } \\
2005^{15}\end{array}$ & Silanization & $\begin{array}{l}\text { Microtensile bond strength test; } \\
\text { SEM analysis }\end{array}$ \\
\hline & $\begin{array}{l}\text { Dietschi and } \\
\text { others, } 2006^{44}\end{array}$ & Adhesive application & $\begin{array}{l}\text { Fatigue test; } \\
\text { SEM and Confocal microscopy analysis }\end{array}$ \\
\hline & $\begin{array}{l}\text { Perdigão and } \\
\text { others, } 2006^{29}\end{array}$ & Silanization & Push-out bond strength test \\
\hline \multirow{15}{*}{$\begin{array}{l}\text { Micro-mechanical } \\
\text { and Chemical } \\
\text { Bonding }\end{array}$} & $\begin{array}{l}\text { Bitter and others, } \\
2006^{25}\end{array}$ & Co-Jet Silanization & $\begin{array}{l}\text { Push-out bond strength test; } \\
\text { SEM analysis }\end{array}$ \\
\hline & $\begin{array}{l}\text { Balbosh and Kern, } \\
2006^{1}\end{array}$ & Sandblasting; Adhesive application & $\begin{array}{l}\text { Thermocycling; Fatigue cycling; } \\
\text { Pull-out test }\end{array}$ \\
\hline & $\begin{array}{l}\text { D'Arcangelo and } \\
\text { others, } 2007^{61}\end{array}$ & $\begin{array}{l}\text { Hydrofluoric acid; Sandblasting; } \\
\text { Silanization }\end{array}$ & $\begin{array}{l}\text { Push-out bond strength test; } \\
\text { SEM analysis }\end{array}$ \\
\hline & $\begin{array}{l}\text { Asmussen and } \\
\text { others, } 2005^{65}\end{array}$ & $\begin{array}{l}\text { Grinding; Sandblasting; Co-Jet; } \\
\text { Alloy primer application }\end{array}$ & Contact angle measurment \\
\hline & $\begin{array}{l}\text { Monticelli and } \\
\text { others, } 2006^{76}\end{array}$ & $\begin{array}{l}\text { Hydrogen peroxide; Sodium ethoxide; } \\
\text { Potassium permanganate; Silanization }\end{array}$ & $\begin{array}{l}\text { Microtensile bond strength test; } \\
\text { SEM analysis }\end{array}$ \\
\hline & $\begin{array}{l}\text { Monticelli and } \\
\text { others, } 2006^{49}\end{array}$ & $\begin{array}{l}\text { Sodium ethoxide; Silane/Adhesive } \\
\text { application }\end{array}$ & $\begin{array}{l}\text { Microtensile bond strength test; } \\
\text { SEM analysis }\end{array}$ \\
\hline & $\begin{array}{l}\text { Monticelli and } \\
\text { others, } 2006^{40}\end{array}$ & Hydrogen peroxide; Silanization & $\begin{array}{l}\text { Microtensile bond strength test; } \\
\text { SEM analysis }\end{array}$ \\
\hline & $\begin{array}{l}\text { Monticelli and } \\
\text { others, } 2006^{83}\end{array}$ & $\begin{array}{l}\text { Hydrogen peroxide; } \\
\text { Silane/Adhesive application }\end{array}$ & $\begin{array}{l}\text { Water storage; theromocycling; } \\
\text { Microtensile bond strength test; } \\
\text { SEM analysis }\end{array}$ \\
\hline & $\begin{array}{l}\text { Monticelli and } \\
\text { others, } 2006^{80}\end{array}$ & Hydrogen peroxide; Silanization & $\begin{array}{l}\text { Microtensile bond strength test; } \\
\text { SEM analysis }\end{array}$ \\
\hline & $\begin{array}{l}\text { Sahafi and } \\
\text { others, } 2003^{31}\end{array}$ & $\begin{array}{l}\text { Sandblasting; Hydrofluoric acid; } \\
\text { Alloy Primer application; Co-Jet }\end{array}$ & Water storage; Shear bond strength test \\
\hline & $\begin{array}{l}\text { Sahafi and } \\
\text { others, } 2004^{58}\end{array}$ & Sandblasting; Co-Jet; Silanization & Water storage; Pull-out test \\
\hline & $\begin{array}{l}\text { Sahafi and } \\
\text { others, } 2004^{64}\end{array}$ & $\begin{array}{l}\text { Sandblasting; Hydrofluoric acid; } \\
\text { Silanization }\end{array}$ & Water storage; Diametral tensile strength \\
\hline & $\begin{array}{l}\text { Radovic and } \\
\text { others, } 2007^{66}\end{array}$ & $\begin{array}{l}\text { Sandblasting; Adhesive application; } \\
\text { Silanization }\end{array}$ & $\begin{array}{l}\text { Microtensile bond strength test; } \\
\text { SEM analysis }\end{array}$ \\
\hline & $\begin{array}{l}\text { Valandro and } \\
\text { others, } 2006^{60}\end{array}$ & $\begin{array}{l}\text { Hydrofluoric acid; phosphoric acid; } \\
\text { Co-Jet; Silanization }\end{array}$ & $\begin{array}{l}\text { Microtensile bond strength test; } \\
\text { SEM analysis }\end{array}$ \\
\hline & $\begin{array}{l}\text { Vano and } \\
\text { others, } 2006^{63}\end{array}$ & $\begin{array}{l}\text { Hydrofluoric acid; Hydrogen peroxide; } \\
\text { Silanization }\end{array}$ & $\begin{array}{l}\text { Microtensile bond strength test; } \\
\text { SEM analysis }\end{array}$ \\
\hline
\end{tabular}

(R): the chemical reaction begins with hydrolysis of the alkoxide groups (R) into silanols ( $\mathrm{SiOH})$ that may condense, forming siloxane bonds (Figure 1)..$^{20-21}$

Silane has been proven to increase ceramic-composite bond strength during luting procedures or when repairing chipped ceramic restorations..$^{22-24}$ Treating the post surface with a silane-coupling agent may be advisable for enhancing adhesion. However, opinion differs about the efficiency of post silanization.
According to some authors, ${ }^{25}$ silane treatment did not enhance the retention of glass fiber posts luted with six different resinous cements. Even if the effects of silanization proved to be significant with regard to bond strengths to FRC posts, the clinical relevance of the differences has been considered to be of minor importance. ${ }^{26}$

Goracci and others recently reported an improvement in bond strength between silanized fiber posts and flowable composites used as core materials. ${ }^{15}$ Similarly, 
Aksornmuang and others and Perdigão and others confirmed the benefit of silane application for enhancing the microtensile bond strength of a dual-cure resin core material to translucent fiber posts. ${ }^{27-29}$

These results rely on silanes' capability to increase surface wettability, creating a chemical bridge with $\mathrm{OH}-$ covered substrates, such as glass. However, the interfacial strength is still relatively low when compared to the values achieved with dental substrates. ${ }^{15,30-31}$

One possible reason is the absence of a chemical union between resin composites (methacrylate-based) and the matrix of fiber posts, which are often made of epoxy resin. Epoxy polymers exhibit a high degree of conversion and highly cross-linked structures. ${ }^{32}$

Amino-silane coupling agents are generally used as adhesion promoters in the presence of epoxy resin polymers. ${ }^{33}$ On the other hand, MPS (methacryloxypropyltrimethoxysilane) silanes are commonly applied in dentistry. ${ }^{21,24}$ Since MPS silane does not bond well with the epoxy matrix, bond strength between the epoxy resin phase of the fiber post and the methacrylate-based resin composite should not be enhanced. A chemical bond through silane may be achieved only between the resin composite and the exposed glass fibers of the post.

This lack of compatibility between the fiber post material and silane blends may have some influence on the way silane molecules can absorb, condense or interact with a substrate. ${ }^{34-35}$

Moreover, silane coupling is a technique-sensitive step. Among factors influencing its efficacy, the composition ( $\mathrm{pH}$, solvent content, molecule size) and application mode are primarily involved. Solvent evaporation plays an important role: while small amounts of solvent may be beneficial to promoting silane wetting, incomplete removal may compromise coupling. ${ }^{36}$

To optimize the mechanism of chemical interaction between silane and an inorganic surface, the reaction may be catalyzed by acid treatment or heating. ${ }^{18,37}$ Heat treatment of silanated glass is routinely performed in the glass industry to maximize bond strength. ${ }^{38}$ Silane has been proven to increase ceramic-composite bond strength during luting procedures, when repairing chipped ceramic restorations ${ }^{22,24,38}$ or when bonding ceramics to resin composite..$^{37,39}$

A similar approach was recently proposed in an attempt to improve silane coupling to translucent fiber posts. ${ }^{40}$ In that study, single-phase pre-activated solutions (Monobond-S, Ivoclar-Vivadent and Porcelain Silane, BJM Lab), based on different silane molecules (3-MPS and GPS, respectively) and a two-component system (Porcelain Liner M, Sun Medical) in which hydrolysis occurs when mixing the silane coupler $(\gamma-$ MPTS) with the acidic monomer (4-META) just before its application, were tested..$^{41-42}$
The selection of a warm air stream $\left(38^{\circ} \mathrm{C}\right)$ for air-drying the fiber post surface seemed to be a clinically-feasible chairside procedure used to overcome some of the problems related to silane composition and/or application..$^{18,37,43}$

Some results recently achieved on ceramics confirmed this aspect, particularly for the two-component systems that have proved to be more sensitive to heating. ${ }^{38,43}$ Some authors and manufacturers have proposed adhesive systems as a possible alternative to silane in fiberpost couplings. ${ }^{44}$ The possible benefit of silanization and the consecutive application of a bonding agent have recently been evaluated with controversial results. Ferrari and others ${ }^{45}$ reported no substantial improvement in bond strength by the separate application of silane and a different formulation of dentin adhesives on methacrylate-based quartz fiber posts. One possible explanation is the formation of a thick multi-phase coupling layer in which flaws may easily be produced during each separate phase of the application. Some recently marketed coupling agents rely on the possibility of combining a silane/primer solution (Clearfil Porcelain Bond Activator, Kuraray) and a bonding agent (Clearfil SE Bond, Kuraray or alternative adhesives from the same manufacturer). In these two-component systems for "on-demand" hydrolysis, the silane is rapidly hydrolyzed when mixed with the acidic phosphate monomers present in the water-containing dentin adhesives. This results in a condensation reaction that enables the trialkoxy silane to perform more efficiently than completely pre-hydrolyzed solutions. ${ }^{46}$ This approach has been shown to improve bond strength to ceramics. ${ }^{47-48}$ Satisfactory results have been reported on both the zirconia and epoxy resin-based translucent fiber posts. ${ }^{27-28,50}$ These combined silane/bonding agents may have an advantage in bonding to the post surface, because of the simultaneous formation of siloxane bonds and the polymerization of functional groups in the resin.

A possible limitation of this technique is represented by the selection of bonding agent. Several newly marketed adhesive systems include large amounts of water and other organic solvents, acidic monomers or 2hydroxyethylmethacrylate. ${ }^{50}$ As a consequence of their composition, simplified one-step self-etch adhesives are considered prone to phase separation of the hydrophobic monomers when the volatile solvent/water ratio is reduced during evaporation, creating a non-uniform interface. This aspect may expedite degradation of the post/composite interface, rendering its potential use with silane coupling agents as questionable. Conversely, the inclusion of a separate hydrophobic resin coating in the two-step adhesives (Clearfil SE Bond or Clearfil Protect Bond, Kuraray) that were applied after the silane/adhesive primer solution contributes to the creation of a more reliable seal of the 
post surface. Nevertheless, chemical adhesion alone may not guarantee a strong, durable fiber post-to-composite bond.

\section{Chemical and Micro-mechanical Bonding to Fiber Posts}

Surface treatments are common methods for improving the general adhesion properties of a material by facilitating chemical and micromechanical retention between the different constituents. In adhesive dentistry, surface conditioning techniques have been developed for natural substrates (enamel, dentin) $)^{5-53}$ and restorative materials.

The concept of conditioning artificial substrates to improve bond strength is exemplified by the etching of Maryland bridges ${ }^{54-55}$ and feldspathic porcelain restorations. ${ }^{24,56-57}$ Based on this principle, different conditioning procedures, initially proposed for ceramics, have also been tested on fiber posts.

\section{Hydrofluoric Acid}

Etching with hydrofluoric acid is intended to create a roughening of the surface, which allows for micromechanical interlocking with the resinous restoration.

Hydrofluoric acid has recently been proposed for etching glass fiber posts (Figure 2A). ${ }^{58-61}$ The effect of the acid has been proven to be time-dependent and influenced by the post composition (type of matrix and/or fibers). This technique produced substantial damage to the glass fibers and affected the integrity of the post. ${ }^{60}$

The glass fibers appeared weaker than quartz fibers. This is due to the extremely corrosive effect of hydrofluoric acid on the glass phase of a ceramic matrix. ${ }^{24,62}$ These findings were confirmed by Vano and others ${ }^{63}$ when hydrofluoric acid was used to condition the methacrylate-based fiber posts: despite the improvement in post-to-composite bond strength, a remarkable surface alteration, ranging from microcracks to longitudinal fractures of the fiber layer, was detected. As a consequence, it is not possible to suggest general guidelines for using hydrofluoric acid in the surface etching of aesthetic fiber posts.

\section{Sandblasting and Silica Coating}

Non-treated fiber posts have a relatively smooth surface area that limits mechanical interlocking between the post surface and resin cement, and purely adhesive failure modes are commonly recorded at the post/composite interfaces (Figure 2B). Sandblasting with alumina particles results in an increased roughness of the surface and surface area. The Co-Jet system (Co-Jet, 3M ESPE, St Paul, MN, USA) for intraoral use is a modification of the Rocatec system introduced for labo-

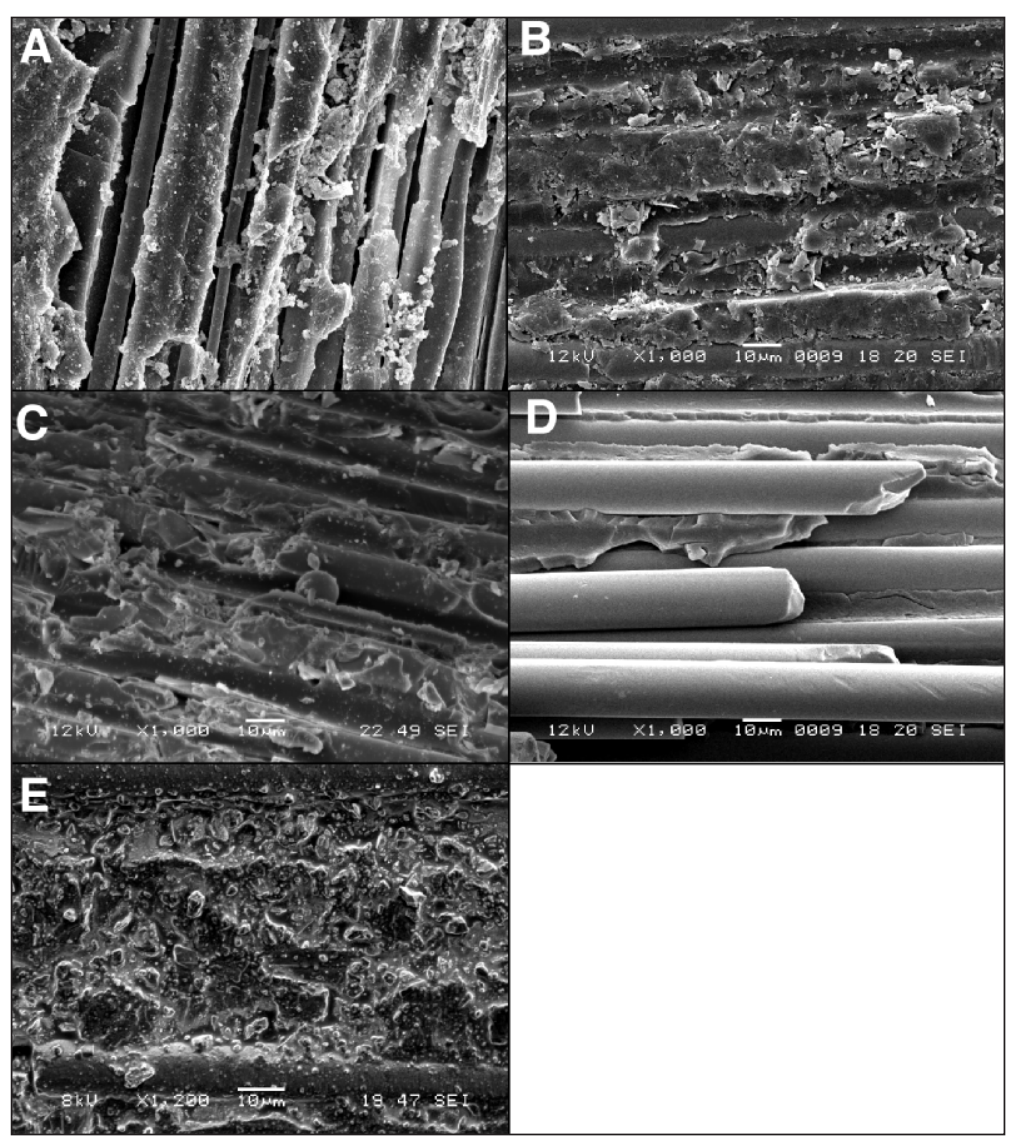

Figure 2: A) Representative SEM micrographs of the fiber post surface after HF etching. Denuded quartz fibers are evident on the post surface, due to deep epoxy resin dissolution (1000x). B) Morphological aspect of the fiber post surface before treatment: no fibers are exposed on the outer surface. which appears embedded in the epoxy resin matrix (1000x bar $10 \mu \mathrm{m})$. C) SEM images of the fiber post surface after sandblasting $(1000 x$ bar $10 \mu \mathrm{m})$ and $\mathrm{D})$ after etching with $10 \%$ hydrogen peroxide for 20 minutes. Exposure of the quartz fibers could be seen as a result of the partial dissolution of the surface epoxy resin. Fibers were not damaged by the etching treatment (1000x bar $10 \mu \mathrm{m})$. E) SEM image of the experimental zirconium oxide industrial coating: particles are detectable on the post surface, thus covering the fibers and the resinous matrix (1200x bar $10 \mu \mathrm{m})$.

ratory use in 1989. This system relies on the use of aluminum oxide particles modified by silica. As a result, a silicate layer is welded onto the post surface by high spot heat produced by blasting pressure in a process called tribochemical coating. These procedures are followed by silanization of the pre-treated fiber post surface, thus combining chemical and micromechanical retention.

Several studies investigated the bonding of resinous materials to different types of posts, evaluating the effect of the surface treatments. Air abrasion with silica-coated aluminum oxide particles creates a layer of silica on the surface of the post due to the high velocity impact of the silica on the substrate, allowing for the penetration of particles of about 15 microns. ${ }^{60}$ This treatment improved the bond strength between quartz FRC posts and resin cements when compared with phosphoric acid or hydrofluoric acid etching. ${ }^{60}$ 
Sahafi and others tested the efficacy of blasting the surface of zirconia and fiber posts with silica oxide (CoJet System). ${ }^{31,64}$ Despite the satisfactory bond strengths achieved, the treatment was considered too aggressive for fiber posts, with the risk of significantly modifying their shape and, consequently, their fit within the root canals. ${ }^{64}$ The application time, size of the particles of alumina and pressure may have influenced the results. On the other hand, this treatment appeared to be beneficial when performed on zirconia posts.

Bitter and others ${ }^{26}$ reported that, depending of the luting materials used, some influence was exerted by the CoJet treatment of the bond strength of fiber posts to resinous cements.

More promising results were recently achieved by Balbosh and Kern ${ }^{1}$ and Asmussen and others. ${ }^{65}$ Epoxy resin-based fiber posts were air-born particle abraded with 50 micron alumina particles at 2.5-bar pressure for five seconds and a distance of $30 \mathrm{~mm}$. This regimen did not produce visible changes to the form of the post. Nevertheless, this regimen resulted in increased surface area and mechanical interlocking with the resin cement. Similarly, Radovic and others ${ }^{66}$ reported a significant increase in surface retention when Rocatec-Pre aluminum oxide particles were used to treat FRC posts: the mechanical action of blasting probably determined removal of the superficial layer of the resinous matrix, creating micro-retentive spaces on the post surface (Figure 2C).

However, the main problem related to these techniques is represented by the lack of selectivity: both the matrix and the fibers of the post are affected by this treatment, sometimes resulting in damage to the post structure.

\section{Alternative Etching Techniques}

To achieve optimal properties in fiber-reinforced composite materials, adhesion between the fibers and the composite is usually optimized through selective superficial preparations. ${ }^{67}$ These treatments allow for modification and improvement of the properties of the interface between the resinous matrix and the fibers.

It was of interest to verify whether, and to what extent, the adhesive potential of the fiber post could be improved as a result of these treatments. Different chemicals and laboratory and industrial techniques have been evaluated in an attempt to find a possible application in dentistry.

As previously reported, the absence of chemical interaction between the methacrylate-based resin composite and epoxy resin matrix of the fiber posts ${ }^{24}$ represents the primary cause of weakness in post-to-composite bonds.

Different solutions and solvents are known to be effective on epoxy resin. ${ }^{68-69}$ Surface pre-treatment of the resin phase of fiber posts may be beneficial in improving their adhesion to methacrylate-based resin composites.

For industrial applications, such as epoxy resin-based circuit boards, many chemical techniques have been introduced to strengthen adhesion between the components of the fiber-reinforced resin composites. ${ }^{70-72}$ In particular, potassium permanganate is usually applied for conditioning epoxy resin surfaces for the metal plating of printed circuits boards..$^{73-75}$

This treatment, commonly defined as desmearing, is a process designed to remove the smeared epoxy resin byproducts from copper surfaces, thus providing superior topography for increased adhesion of direct metallization or electroless copper.

This procedure, consisting of the subsequent application of three chemical solutions (swelling, etching and neutralizing), was tested on translucent fiber posts, achieving noteworthy results. ${ }^{76}$

With a similar purpose, hydrogen peroxide and sodium ethoxide are commonly employed in immunological electron microscopy to partially dissolve the resin surface of epoxy resin-embedded tissue sections and expose tissue epitopes for immunolabeling enhancement. The etching effect of these chemicals depends on the capacity to partially dissolve the resin matrix, breaking epoxy resin bonds through a mechanism of substrate oxidation. ${ }^{68,77-79}$

A similar approach has been proposed in dentistry for the surface pre-treatment of fiber posts to increase their responsiveness to silanization. It has achieved satisfactory results for both chemicals tested. ${ }^{49,80}$ The surface conditioning treatment consisted of immersion of the fiber posts into the solutions for a relatively short time (10-20 minutes), thus allowing for modification of the post surface morphology (Figure 2D).

By removing a surface layer of the epoxy resin, a greater surface area of exposed quartz fibers is available for silanization. The spaces between these fibers provide additional sites for micromechanical retention of the resin composites. This retention concept is reminiscent of the creation of hybrid layers in dentin, ${ }^{81}$ as the interface is contributed to by both quartz fibers from the fiber post and the methacrylate resin matrix. In particular, $\mathrm{H}_{2} \mathrm{O}_{2}$ etching ( $10 \% \mathrm{H}_{2} \mathrm{O}_{2}$ for 20 minutes) provided an easy, clinically feasible method for enhancing the interfacial strength between fiber posts and resin composites without the need to employ extremely corrosive liquids in a clinical setting. ${ }^{80}$

\section{FUTURE DIRECTIONS}

Surface post treatments represent one important factor when dealing with epoxy resin-based fiber posts. Clinicians should be aware of the specific indications for treatment that they can perform. 
However, chairside post pre-treatments are still considered a technique-sensitive step. In an attempt to simplify clinical procedures, instituting industrial conditioning of the fiber post surface may be of some help.

For this purpose, pre-coated epoxy resin-based fiber posts have been recently proposed. Although only preliminary in vitro bond strength tests have been performed (Radovic, unpublished results), the zirconium oxide post surface coating provided by the manufacturer has offered sufficient interfacial strength with composites (Figure 2E).

Silica-containing films are assumed to provide excellent surface properties, thanks to the stability of their bonds and their ability to form highly hydrophobic substrates..$^{81-82}$ Moreover, the epoxy resin matrix of the post is not directly involved in the adhesion mechanism, avoiding the risk of incompatibility with methacrylate-based restorative materials. ${ }^{80}$ Further investigations are needed to evaluate the long-term durability of these bonds through accelerated aging conditions..$^{83,64}$

From a manufacturing perspective, alternative strategies, based on the combination of micromechanical and chemical conditioning of the post surface, are advisable to improve retention, thus achieving more reliable adhesion. The use of plasma technology may be an example: this technique has a wide range of applications and provides several types of surface treatments when materials have to be combined or when surfaces need special modifications. ${ }^{84-86}$ Some application fields are represented by etching (microsandblasting by ion bombardment) and surface coating through plasma polymerization. The potential for this technique in fiber post pre-coating should be assessed.

\section{CONCLUSIONS}

The trend in clinical practice is towards fiber posts, and the literature generally encourages their application. Most in vitro and in vivo studies agree that the failure mode of fiber posts is more favorable than with metal posts, and the level of success seen in short-term published clinical studies is being confirmed by ongoing long-term evaluations. If certain basic principles are followed, it is possible to achieve high levels of clinical success with most of the current fiber posts on the market today.

\section{(Received 30 April 2007)}

\section{References}

1. Balbosh A \& Kern M (2006) Effect of surface treatment on retention of glass-fiber endodontic posts Journal of Prosthetic Dentistry 95(3) 218-223.
2. Stockton LW (1999) Factors affecting retention of post systems: A literature review Journal of Prosthetic Dentistry 81(4) $380-385$.

3. Nergiz I, Schmage P, Ozcan M \& Platzer U (2002) Effect of length and diameter of tapered posts on the retention Journal of Oral Rehabilitation 29(1) 28-34.

4. Cohen BI, Pagnillo MK, Newman I, Musikant BL \& Deutsch AS (1998) Retention of three endodontic posts cemented with five dental cements Journal of Prosthetic Dentistry 79(5) 520-525.

5. Cohen BI, Musikant BL \& Deutsch AS (1992) Comparison of retentive properties of four post systems Journal of Prosthetic Dentistry 68(2) 264-268.

6. Ferrari M, Vichi A \& Grandini S (2001) Efficacy of different adhesive techniques on bonding to root canal walls: An SEM investigation Dental Materials 17(5) 422-429.

7. Ngoh EC, Pashley DH, Loushine RJ, Weller N \& Kimbrough F (2001) Effects of eugenol on resin bond strengths to root canal dentin Journal of Endodontics 27(6) 411-414.

8. Ari H, Yasar E \& Belli S (2003) Effects of $\mathrm{NaOCl}$ on bond strength of resin cement to root canal dentin Journal of Endodontics 29(4) 248-251.

9. Ferrari M, Grandini S, Simonetti M, Monticelli F \& Goracci C (2002) Influence of a microbrush on bonding fiber posts into root canals under clinical conditions Oral Surgery, Oral Medicine, Oral Pathology, Oral Radiology and Endodontics 94(5) 627-631.

10. O'Keefe KL \& Powers JM (2001) Adhesion of resin composite core materials to dentin International Journal of Prosthodontics 14(5) 451-456.

11. Chersoni S, Acquaviva GL, Prati C, Ferrari M, Grandini S, Pashley DH \& Tay FR (2005) In vivo fluid movement through dentin adhesives in endodontically treated teeth Journal of Dental Research 84(3) 223-227.

12. Ferrari M, Vichi A, Mannocci F \& Mason PN (2000) Retrospective study of clinical performance of fiber posts The American Journal of Dentistry 13(Spec No) 9B-13B.

13. Ferrari M, Vichi A \& García-Godoy F (2000) Clinical evaluation of fiber-reinforced epoxy resin posts and cast post and cores The American Journal of Dentistry 13(Spec No) 15B$18 \mathrm{~B}$.

14. Malferrari S, Monaco C \& Scotti R (2003) Clinical evaluation of teeth restored with quartz fiber-reinforced epoxy resin posts International Journal of Prosthodontics 16(1) 39-44.

15. Goracci C, Raffaelli O, Monticelli F, Balleri P, Bertelli E \& Ferrari M (2005) The adhesion between fiber posts and composite resin cores: Microtensile bond strength with and without post silanization Dental Materials 21(5) 437-444.

16. Castellucci A \& Becciani R (2004) [Ricostruzione postendodontica dei denti compromessi. Aspetti biomeccanici] Dental Cadmos 2 2-21.

17. Schwartz RS \& Robbins JW (2004) Post placement and restoration of endodontically treated teeth: A literature review Journal of Endodontics 30(5) 289-301.

18. Plueddemann EP (1991) Silane Coupling Agents New York Plenum Press.

19. Mittal KL (1992) Silane and Other Coupling Agents VSP Utrecht The Netherlands 21-22. 
20. Daniels MW \& Francis LF (1998) Silane adsorption behaviour, microstructure, and properties of glycidoxypropyltrimethoxysilane-modified colloidal silica coatings Journal of Colloid and Interface Science 205(1) 191-200.

21. Matinlinna JP, Özcan M, Lassila LVJ \& Vallittu PK (2004) The effect of a 3-methacryloxypropyltrimethoxysilane and vinyltriisopropoxysilane blend and tris (3-trimethoxysilylpropyl)isocyanurate on shear bond strength of composite resin to titanium metal Dental Materials 20(9) 804-813.

22. Della Bona A, Anusavice KJ \& Shen C (2000) Microtensile strength of composite to hot-pressed ceramics Journal of Adhesive Dentistry 2(4) 305-313.

23. Barghi N (2000) To silanate or not to silanate: Making a clinical decision Compendium of Continuing Education in Dentistry 21(8) 659-662.

24. Özcan M \& Vallittu PK (2004) Effect of surface conditioning methods on the bond strength of luting cements to ceramics Dental Materials 19(8) 725-731.

25. Bitter K, Meyer-Luckel H, Priehn K, Martus P \& Kielbassa AM (2006) Bond strengths of resin cements to fiber-reinforced composite posts American Journal of Dentistry 19(3) 138-142.

26. Bitter K, Noetzel J, Neumann K \& Kielbassa AM (2007) Effect of silanization on bond strengths of fiber posts to various resin cements Quintessence International 38(2) 121-128.

27. Aksornmuang J, Foxton RM, Nakajima M \& Tagami J (2004) Microtensile bond strength of a dual cure resin core material to glass and quartz fibre posts Journal of Dentistry 32(6) 443-450.

28. Aksornmuang J, Nakajima M, Foxton RM \& Tagami J (2006) Regional bond strengths of a dual-cure resin core material to translucent fiber posts American Journal of Dentistry 19(1) 51-55.

29. Perdigão J, Gomes G \& Lee IK (2006) The effect of silane on the bond strengths of fiber posts Dental Materials 22(8) 752-758.

30. Cardoso PE, Sadek FT, Goracci C \& Ferrari M (2002) Adhesion testing with the microtensile method: Effect of dental substrate and adhesive system on bond strength measurement Journal of Adhesive Dentistry 4(4) 291-297.

31. Sahafi A, Peutzfeldt A, Asmussen E \& Gotfredsen K (2003) Bond strength of resin cement to surface-treated posts of titanium alloy, glass fiber, and zirconia, and to dentin Journal of Adhesive Dentistry 5(2) 153-162.

32. Lassilla LVJ, Tonner J, le-Bell AM, Narva K \& Vallittu PK (2004) Flexural properties of fiber reinforced root canal posts Dental Materials 20(1) 29-36.

33. Park SJ \& Jin JS (2001) Effect of silane coupling agent on interphase and performance of glass fibers/unsaturated polyester composites Journal of Colloid and Interface Science 242(1) 174-179.

34. Wu HF, Dwight DW \& Huff NT (1997) Effect of silane coupling agents in the interphase and performance of glass-fiberreinforced polymer composites Composite Science and Technology 57(8) 975-983.

35. Liu Q, Ding J, Chambers DE, Debnath S, Wunder SL \& Baran GR (2001) Filler-coupling agent-matrix interactions in silica/polymethylmethacrylate composites Journal of Biomedical Material Research 57(3) 384-393.
36. de la Fuente JL \& Madruga EL (1999) Solvent effects on freeradical copolymerization of butyl acrylate with methyl methacrylate Macromolecular Chemistry and Physics 200(7) 1639-43.

37. Shen C, Oh W \& Williams JR (2004) Effect of post-silanization drying on the bond strength of composite to ceramic The Journal of Prosthetic Dentistry 91(5) 453-458.

38. Barghi N, Berry T \& Chung K (2000) Effects of timing and heat treatment of silanated porcelain on the bond strength Journal of Oral Rehabilitation 27(5) 407-412.

39. Nogami T, Tanoue N, Atsuta M \& Matsumura H (2004) Effectiveness of two-liquid silane primers on bonding sintered feldspathic porcelain with a dual-cured composite luting agent Journal of Oral Rehabilitation 31(8) 770-774.

40. Monticelli F, Toledano M, Osorio R \& Ferrari M (2006) Effect of temperature on the silane coupling agents when bonding core resin to quartz fibre posts Dental Materials 22(11) 10241028.

41. Filho AM. Vieira LCC, Araújo E \& Monteiro Junior S (2004) Effect of different ceramic surface treatments on resin microtensile bond strength Journal of Prosthodontics 13(1) 28-35.

42. Kato H, Matsumura T, Ide T \& Atsuta M (2001) Improved bonding of adhesive resin to sintered porcelain with the combination of acid etching and two-liquid silane conditioner Journal of Oral Rehabilitation 28(1) 102-108.

43. Hooshmand T, van Noort R \& Keshvad A (2002) Bond durability of the resin-bonded and silane treated ceramic surface Dental Materials 18(2) 179-188.

44. Dietschi D, Ardu S, Rossier-Gerber A \& Krejci I (2006) Adaptation of adhesive post and cores to dentin after in vitro occlusal loading: Evaluation of post material influence Journal of Adhesive Dentistry 8(6) 409-419.

45. Ferrari M, Goracci C, Sadek FT, Monticelli F \& Tay FR (2006) An investigation of the interfacial strengths of methacrylate resin-based glass fiber post-core buildups Journal of Adhesive Dentistry 8(4) 239-245.

46. Foxton RM, Pereira PN, Masatoshi N, Tagami J \& Miura H (2002) Long-term durability of the dual-cure resin cement/silicon oxide ceramic bond Journal of Prosthetic Dentistry 4(2) 125-135.

47. De Munck J, Vargas M, Van Landuyt K, Hikita K, Lambrechts P \& Van Meerbeek B (2004) Bonding of an autoadhesive luting material to enamel and dentin Dental Materials 20(10) 963-971.

48. Blatz MB, Sadan AS, Martin J \& Lang BR (2004) In vitro evaluation of shear bond strengths of resin to densely-sintered high-purity zirconium-oxide ceramic after long-term storage and thermal cycling Journal of Prosthetic Dentistry 91(4) $356-362$

49. Monticelli F, Osorio R, Toledano M, Tay FR, Goracci C \& Ferrari M (2006) Improving the quality of the quartz fiber post-core bond using sodium ethoxide etching and combined silane/adhesive coupling Journal of Endodontics 32(5) 447-451.

50. Hashimoto M, De Munck J, Ito S, Sano H, Kaga M, Oguchi H, Van Meerbeek B \& Pashley DH (2004) In vitro effect of nanoleakage on resin-dentin bond strengths analyzed by microtensile bond test, SEM/EDX and TEM Biomaterials 25(25) 5565-5574. 
51. Buonocore MG (1955) A simple method of increasing the adhesion of acrylic filling materials to enamel Journal of Dental Research 34(6) 849-853.

52. Nakabayashi N, Nakamura M \& Yasuda N (1991) Hybrid layer as a dentin bonding mechanism Journal of Esthetic Dentistry 3(4) 133-138.

53. Nakabayashi N (1982) Resin reinforced dentin due to infiltration of monomers into dentine at the adhesive interface Journal of Japanese Society of Dental Materials 1 78-81.

54. Thompson VP, Del Castillo E \& Livaditis GJ (1983) Resinbonded retainers. Part I: Resin bond to electrolytically etched non-precious alloys Journal of Prosthetic Dentistry 50(6) 771779 .

55. Thompson VP (1984) Etching cobalt/chrome alloys for Maryland bridges Trends and Techniques in the Contemporary Dental Laboratory 1(2) 41-46.

56. Horn HR (1983) Porcelain laminate veneers bonded to etched enamel In Phillips RW, editor. Symposium on Dental Material Dental Clinics of North America 27(4) 671-684.

57. Borges GA, Sophr AM, de Goes MF, Sobrinho LC \& Chan DC (2003) Effect of etching and airborne particle abrasion on the microstructure of different dental ceramics Journal of Prosthetic Dentistry 89(5) 479-488.

58. Sahafi A, Peutzfeldt A, Asmussen E \& Gotfredsen K (2004) Effect of surface treatment of prefabricated posts on bonding of resin cements Operative Dentistry 29(1) 60-68.

59. Dallari A \& Mason PN (2004) [Restauri estetici con perni endocanalari in fibre di quarzo] Esthetic restorations with quartz fiber posts Martina Ed Bologna 23-26.

60. Valandro LF, Yoshiga S, de Melo RM, Galhano GA, Mallmann A, Marinho CP \& Bottino MA (2006) Microtensile bond strength between a quartz fiber post and a resin cement: Effect of post surface conditioning Journal of Adhesive Dentistry 8(2) 105-111.

61. D'Arcangelo C, D'Amario M, Prosperi GD, Cinelli M, Giannoni M \& Caputi S (2007) Effect of surface treatments on tensile bond strength and on morphology of quartz-fiber posts Journal of Endodontics 33(3) 264-267.

62. Addison O \& Fleming GJP (2004) The influence of cement lute, thermocycling and surface preparation on the strength of a porcelain veneering material Dental Materials 20(3) 286-292.

63. Vano M, Goracci C, Monticelli F, Tognini F, Gabriele M, Tay FR \& Ferrari M (2006) The adhesion between fibre posts and composite resin cores: The evaluation of microtensile bond strength following various surface chemical treatments to posts International Endodontic Journal 39(1) 31-39.

64. Sahafi A, Peutzfeldt A, Asmussen E \& Gotfredsen K (2004) Retention and failure morphology of prefabricated posts International Journal of Prosthodontics 17(3) 307-312.

65. Asmussen E, Peutzfeldt A \& Sahafi A (2005) Bonding of resin cements to post materials: Influence of surface energy characteristics Journal of Adhesive Dentistry 7(3) 231-234.

66. Radovic I, Monticelli F, Goracci C, Cury AH, Coniglio I, Vulicevic ZR, García-Godoy F \& Ferrari M (2007) The effect of sandblasting on adhesion of a dual-cured resin composite to methacrylic fiber posts: Microtensile bond strength and SEM evaluation Journal of Dentistry 35(6) 496-502.
67. Iglesias JG, Gonzàles-Benito J, Aznar AJ, Bravo J \& Balsega $J$ (2002) Effect of glass fiber surface treatment on mechanical strength of epoxy based composite materials Journal of Colloid and Interface Science 250(1) 251-260.

68. Bronson SH, Hansen AR, Nielsen HZ \& Woxen IK (2001) A comparative study of the immunogold labeling on $\mathrm{H}_{2} \mathrm{O}_{2}$-treated and heated epoxy sections Micron 32(2) 147-151.

69. Bronson SH (2003) Deplasticizing or etching of epoxy sections with different concentration of sodium ethoxide to enhance the immunogold labeling Micron 32(2) 101-105.

70. Cheng TH, Jones FR \& Wang D (1993) Effect of fibre conditioning on the interfacial shear strength of glass fibre composites Composite Science and Technology 48(89) 89-96.

71. Crasa JJ, Rowe-Tattib CA, Nivensb DA \& Ligler FS (1999) Comparison of chemical cleaning methods of glass preparation for silanization Biosensors \& Bioelectronics 14(8) 683688.

72. Roizard X, Wery M \& Kirmann J (2002) Effects of alkaline etching on the surface roughness of a fibre-reinforced epoxy composite Composite Structure 56(3) 223-228.

73. Mann D, Fessmann J, Kampschulte G \& Hopkins M (1991) Adherent metallization of plastic composites Surface and Coatings Technology 49(11) 168-173.

74. Kirmann J, Roizard X, Pagetti J \& Halut J (1998) Effect of alkaline permanganate etching of epoxy on the peel adhesion of electrolessly plated copper on a fibre reinforced epoxy composite Journal of Adhesion Science and Technology 12(4) 383398.

75. Thorm CE \& Walsh MK (1991) The mechanism of permanganate desmearing Printed Circuits Boards \& Fabrication 25 30-32.

76. Monticelli F, Toledano M, Tay FR, Cury AH, Goracci C \& Ferrari M (2006) Post-surface conditioning improves interfacial adhesion in post/core restorations Dental Materials 22(7) 602-609.

77. Holm R, Farrants GW, Nesland JM, Sobrinho-Simoes M, Jørgensen OG \& Johanessen JV (1989) Ultrastructural and electron immuno-histochemical features of medullary thyroid carcinoma Virchows Archive A: Pathological Anatomy and Histology A4(14) 375-384.

78. Enerström S \& Kniola B (1995) Resin embedding for quantitative immunoelectron microscopy: A comparative computerized image analysis Biotechnic \& Histochemistry 70(3) 135-146.

79. Baskin DG, Erlandsen SL \& Parson JA (1979) Influence of hydrogen peroxide or alcoholic sodium hydroxide on the immunocytochemical detection of growth hormone and prolactin after osmium fixation Journal of Histochemistry and Cytochemistry 27(9) 1290-1292.

80. Monticelli F, Toledano M, Tay FR, Sadek FT, Goracci C \& Ferrari M (2006) A simple etching technique for improving the retention of fiber posts to resin composites Journal of Endodontics 32(1) 44-47.

81. Daoud WA, Xin JH \& Tao X (2004) Superhydrophobic silica nanocomposite coating by a low-temperature process Journal of the American Ceramic Society 87(9) 1782-1784.

82. Yoshida K, Tanagawa M, Kamada K, Hatada R, Baba K, Inoi T \& Atsuta M (1999) Silica coatings formed on noble dental casting alloy by the sol-gel dipping process Journal of Biomedical Material Research 46(2) 221-227. 
83. Monticelli F, Osorio R, Toledano M, Tay FR \& Ferrari M (2006) In vitro hydrolytic degradation of composite quartz fiber-post bonds created by hydrophilic silane couplings Operative Dentistry 31(6) 728-733.

84. Vichi A, Grandini S \& Ferrari M (2002) Comparison between two clinical procedures for bonding fiber posts into root canal: A microscopic investigation Journal of Endodontics 28(5) 355-360.
85. Fernandes JCS, Ferreira MGS, Haddow DB, Goruppa A, Short R \& Dixon DG (2002) Plasma-polymerised coatings used as pre-treatment for aluminium alloys Surface and Coatings Technology 154(1) 8-13.

86. Mahlberg R, Niem HEM, Denes F \& Rowell RM (1998) Effect of oxygen and hexamethyldisiloxane plasma on morphology, wettability and adhesion properties of polypropylene and lignocellulosics International Journal of Adhesion \& Adhesives 62(18) 283-297. 